NASA/TM-1998-208656

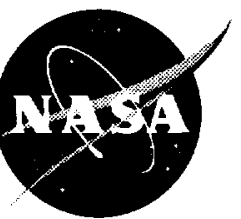

\title{
Emittance Theory for Cylindrical Fiber Selective Emitter
}

Donald L. Chubb

Lewis Research Center, Cleveland, Ohio

Prepared for the

Fourth Conference on Thermophotovoltaic Generation of Electricity (TPV4) sponsored by the National Renewable Energy Laboratory

Denver, Colorado, October 11-14, 1998

National Aeronautics and

Space Administration

Lewis Research Center 
Available from

NASA Center for Aerospace Information 7121 Standard Drive

Hanover, MD 21076

Price Code: A03
National Technical Information Service 5285 Port Royal Road Springfield, VA 22100 Price Code: A03 


\title{
EMITTANCE THEORY FOR CYLINDRICAL FIBER SELECTIVE EMITTER
}

\author{
Donald L. Chubb \\ National Aeronautics and Space Administration \\ Lewis Research Center \\ Cleveland, Ohio 441.35
}

\begin{abstract}
A fibrous rare earth selective emitter is approximated as an infinitely long cylinder. The spectral emittance, $\varepsilon_{\lambda}$, is obtained by solving the radiative transfer equations with appropriate boundary conditions and uniform temperature. For optical depths, $K_{R}=\alpha_{\lambda} R$, where $\alpha_{\lambda}$ is the extinction coefficient and $R$ is the cylinder radius, greater than I the spectral emittance is nearly at its maximum value. There is an optimum cylinder radius. $R_{\text {opr }}$, for maximum emitter efficiency, $\eta_{E}$. Values for $R_{\text {opt }}$ are strongly dependent on the number of emission bands of the material. The optimum radius decreases slowly with increasing emitter temperature, while the maximum efficiency and useful radiated power increase rapidly with increasing temperature.
\end{abstract}

\section{INTRODUCTION}

Fibrous rare earth oxide selective emitters for thermophotovoltaic (TPV) applications have been of research interest for several years. Nelson (1) began working with fibrous emitters in the 1980's. In addition fibrous emitters are being developed at Quantum Group (2) and the Auburn Space Power Institute (3). This paper develops the emittance theory for a fibrous emitter by approximating the emitter as an infinitely long cylinder. Since the fibrous emitters consist of bundles of 1 to $10 \mu \mathrm{m}$ diameter fibers this theory does not include the effects of the reflectance that occurs when radiation leaves a fiber and enters an adjoining fiber. The whole bundle of fibers is being approximated as a continuous cylinder. If the fibers are closely packed and the reflectance at the interface between a fiber and the medium in the voids between fibers is small, then the error resulting from the approximation should be small.

The spectral emittance of the cylinder is obtained by solving the radiative transfer equation with appropriate boundary conditions. Knowing the spectral emittance allows the emitter efficiency to be calculated. As an example, emitter efficiency is calculated for an erbium-holmium aluminum garnet and thulium aluminum garnet $\left(\mathrm{Tm}_{3} \mathrm{Al}_{5} \mathrm{O}_{12}\right)$ which are being studied at NASA Lewis.

\section{TEMPERATURE OF EMITTING CYLINDER}

As pointed out earlier (4), temperature drop across a planar or film type emitter causes a major reduction in the spectral emittance in the emission band of a selective emitter. However, in most cases for a cylindrical emitter there will be a negligible temperature drop. This can be seen by considering the steady state energy equation for an infinite cylinder with no internal heat generation and thermal conductivity, $k_{t h}$, and where we assume the temperature, $T$, and radiation flux, $Q$, depend only on the radial coordinate, $r$.

$$
r\left[k_{t h} \frac{d T}{d r}-Q\right]=\text { constant }
$$

In order to avoid the term in brackets being singular at $r=0$ it must vanish for all $r$. Thus at all $r$ the conduction and radiation fluxes balance.

$$
\mathrm{k}_{\mathrm{th}} \frac{\mathrm{dT}}{\mathrm{dr}}=\mathrm{Q}
$$


In other words. for all steady state conditions all the thermal energy being conducted into the cylinder at the outer radius, $r=R$, leaves the cylinder as radiation.

The radiation flux, $\mathrm{Q}$, will always be less than the blackbody flux $\sigma_{\mathrm{sb}} \mathrm{T}^{4}$, where $\sigma_{\mathrm{sb}}=5.67 \times 10^{-12} \mathrm{w} / \mathrm{cm}^{2} \mathrm{~K}^{4}$ is the Stefan Boltzmann constant. Therefore, define the following dimensioniess variables.

$$
\bar{Q}=\frac{Q}{\sigma_{\mathrm{sb}} \mathrm{T}_{\mathrm{s}}^{4}} \quad \overline{\mathrm{T}}=\frac{\mathrm{T}}{\mathrm{T}_{\mathrm{s}}} \quad \overline{\mathrm{r}}:=\frac{\mathrm{r}}{\mathrm{R}}
$$

Where $T_{s}$ is the temperature at $r=R$. In this case equation (2) becomes the following.

$$
\frac{\mathrm{d} \overline{\mathrm{T}}}{\mathrm{d} \overline{\mathrm{r}}}=\gamma \overline{\mathrm{Q}}
$$

Where $\gamma$ is the ratio of the radiation flux to the thermal conduction flux.

$$
\gamma \equiv \frac{\sigma_{\mathrm{sb}} \mathrm{T}_{\mathrm{s}}^{4}}{\mathrm{k}_{\mathrm{th}} \frac{\mathrm{T}_{\mathrm{s}}}{\mathrm{R}}}=\frac{\sigma_{\mathrm{sh}} \mathrm{T}_{\mathrm{s}}^{3} \mathrm{R}}{\mathrm{k}_{\mathrm{th}}}
$$

For the ceramic materials used in most selective emitters. $\mathrm{k}_{\mathrm{th}} \geq 0.01 \mathrm{w} / \mathrm{cmK}$. Also, for TPV applications $\mathrm{T}_{\mathrm{s}} \leq 2000 \mathrm{~K}$. Therefore, $\gamma \leq 4.5 R(\mathrm{~cm})$. So that if $R<0.1 \mathrm{~cm}$ it is a reasonable approximation to neglect the right hand side of equation (4) and obtain the result $\overline{\mathrm{T}}=$ constant $\left(\mathrm{T}=\mathrm{T}_{\mathrm{s}}\right.$ ). If $\gamma<\mathrm{I}$ for a film or planar emitter then a linear temperature variation results (4) rather than a uniform temperature. For the cylinder emittance calculation that follows, a uniform temperature is assumed.

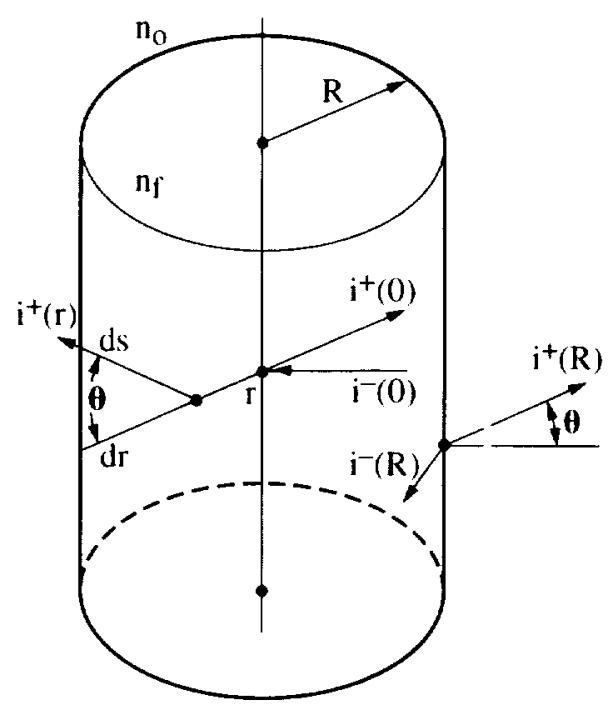

$\mathrm{n}_{\mathrm{f}}=$ index of refraction of cylinider

$\mathrm{n}_{\mathrm{O}}=$ index of refraction of surroundings $\cos \theta \mathrm{ds}=\mathrm{dr}$

FIGURE 1. Schematic of emitting cylinder. 


\section{SPECTRAL EMITTANCE OF CYLINDER}

The spectral emittance is defined as follows.

$$
\varepsilon_{\lambda} \equiv \frac{q_{\lambda}(R)}{e_{b s}\left(\lambda, T_{s}\right)}
$$

Where $\mathrm{q}_{\lambda}(\mathrm{R})$ is the radiation flux leaving the cylinder at $\mathrm{r}=\mathrm{R}$ and $\mathrm{e}_{\mathrm{hs}}\left(\lambda . \mathrm{T}_{\mathrm{s}}\right)$ is the blackbody emissive power where $\lambda$ is wavelength and $T_{s}$ is the cylinder temperature.

$$
\operatorname{ebs}\left(\lambda, T_{s}\right)=\pi i_{b s}\left(\lambda, T_{s}\right)=\frac{2 \pi h c_{o}^{2}}{\lambda^{5}\left[\exp _{\left.\left(h c_{o} / \lambda k T_{s}\right)-1\right]}\right.}
$$

Appearing in equation (7) is the blackbody intensity $i_{b s}\left(\lambda, T_{s}\right), w / \mathrm{cm}^{2} \mathrm{~nm}$ steradian, Planck's constant, $h$,

Boltzmann's constant, $k$, and the vacuum speed of light. $c_{0}$. The radiation flux, $q_{\lambda}(R)$, is obtained by solving the radiation transfer equations for the intensities, $i_{\lambda}{ }^{+}(R)$, and $i_{\lambda}{ }^{-}(R)$. Where $i_{\lambda}{ }^{+}(R)$ is the intensity moving in the $+R$ direction and $i_{\lambda}{ }^{-}(R)$ is the intensity moving in the $-R$ direction as shown in figure 1 . Assuming the intensities depend only on the radial coordinate leads to transport equations for $i_{\lambda}{ }^{+}(R)$ and $i_{\lambda}{ }^{-}(R)$ identical to the planar case (5). These equations are written in terms of the optical depth, $K$, rather than the coordinate. $r$.

$$
\begin{gathered}
\mathrm{K}=\alpha_{\lambda} r \\
\mathrm{~K}_{\mathrm{R}}=\alpha_{\lambda} \mathrm{R}
\end{gathered}
$$

Where $a_{\lambda}$ is the extinction coefficient. assumed independent of $r$, and is the sum of the absorption coefficient. $a_{\lambda}$. and the scattering coefficient $\sigma_{\lambda}$.

$$
\alpha_{\lambda}=a_{\lambda}+\sigma_{\lambda}
$$

The boundary conditions that must be applied are the following. At $r=K=0$, from symmetry conditions.

$$
\mathrm{i}_{\lambda}^{+}(0)=\mathrm{i}_{\bar{\lambda}}(0) \quad \text { at } \quad \mathrm{K}=0
$$

At $r=R$ or $K=K_{R}$ the intensity moving in the $-R$ direction is equal to the reflected intensity.

$$
i_{\lambda}^{-}\left(K_{R}\right)=\rho_{\text {fo }} i_{\lambda}^{+}\left(K_{R}\right) \quad \text { at } \quad K=K_{R}
$$

Where $\rho_{f_{0}}$ is the reflectance at the cylinder outer radius, $R$. At $r=R$ total reflectance occurs for certain angles of incidence, $\theta$. At an interface between a material with a index of refraction, $n_{i}$, and a material with index of refraction, $n_{j}$, where $n_{i}>n_{j}$, radiation moving from $i$ into $j$ with angles of incidence $\theta>\theta_{M}$, where $\theta_{M}$ is given by Snell's Law will be totally reflected. Since $n_{f}>n_{o}$, for the cylinder-air interface we have the following result for the reflectance, $\rho_{f_{0}}$.

$$
\rho_{\text {fo }}=1 \text { for } \theta \geq \theta_{M} \text { where } \mu_{M}^{2} \equiv \cos ^{2} \theta_{M}=1-\left(\frac{n_{0}}{n_{f}}\right)^{2}
$$

For the case where $\theta<\theta_{M}\left(\mu>\mu_{M}\right)$ we approximate $\rho_{f_{0}}$ by the reflectance for normal incidence (6). 


$$
\rho_{\text {fo }}=\left(\frac{n_{f}-n_{o}}{n_{f}+n_{o}}\right)^{2} \theta<\theta_{M}\left(\mu>\mu_{M}\right)
$$

Once the intensities $i_{\lambda}^{+}\left(K_{R}, \theta\right)$ and $i_{\lambda}^{-}\left(K_{R}, \theta\right)$ are obtained the radiation flux. $q_{\lambda}\left(K_{R}\right)$, can be calculated.

$$
\begin{gathered}
\mathrm{q} \lambda\left(\mathrm{K}_{\mathrm{R}}\right)=\mathrm{q}_{\lambda}^{+}\left(\mathrm{K}_{\mathrm{R}}\right)-\mathrm{q} \bar{\lambda}\left(\mathrm{K}_{\mathrm{R}}\right) \\
\mathrm{q}_{\lambda}^{+}\left(\mathrm{K}_{\mathrm{R}}\right)=2 \pi \int_{\theta=0}^{\pi / 2} \mathrm{i}_{\lambda}^{+}\left(\mathrm{K}_{\mathrm{R}}, \theta\right) \cos \theta \sin \theta \mathrm{d} \theta=2 \pi \int_{0}^{1} \mathrm{i}_{\lambda}^{+}\left(\mathrm{K}_{\mathrm{R}}, \mu\right) \mu \mathrm{d} \mu \\
\mathrm{q} \bar{\lambda}\left(\mathrm{K}_{\mathrm{R}}\right)=-2 \pi \int_{\theta=\pi / 2}^{\pi} \mathrm{i} \bar{\lambda}\left(\mathrm{K}_{\mathrm{R}}, \theta\right) \cos \theta \sin \theta \mathrm{d} \theta=2 \pi \int_{0}^{1} \mathrm{i} \bar{\lambda}(0, \mu) \mu \mathrm{d} \mu
\end{gathered}
$$

Solution of the radiative transfer equations for $q_{\lambda}\left(K_{R}\right)$ is presented in (5) for the film or planar case with a linear temperature variation through the film and for no scattering $\left(\sigma_{\mathrm{s}}=0\right.$ in eq. (9)). Results for the uniform temperature cylinder can be obtained from these results by setting $\varepsilon_{\mathrm{fs}}=0\left(\rho_{\mathrm{fs}}=1\right)$ and $\Delta \mathrm{T}=0$ in equations (33) to (36) of reference (5). When this is done the following result is obtained for the spectral emittance.

$$
\varepsilon_{\lambda}=\frac{n_{o}^{2}\left(1-\rho_{f_{o}}\right)\left[1-4 E_{3}^{2}\left(K_{R}\right)\right]}{1-4 E_{3}\left(K_{R}\right)\left[\rho_{f_{o}} E_{3}\left(K_{R}\right)+\mu_{M}^{2}\left(1-\rho_{f_{o}}\right) E_{3}\left(\frac{K_{R}}{\mu_{M}}\right)\right]}
$$

uniform temperature and no scattering

Appearing in equation (15) is the exponential integral $\mathrm{E}_{3}(\mathrm{x})$ defined as follows.

$$
E_{n}(x)=\int_{0}^{1} z^{n-2} \exp \left(-\frac{x}{z}\right) 1 z
$$

The reflectance, $\rho_{\mathrm{fo}}$, is given by equation ( $\left.11 \mathrm{~b}\right)$ and $\mu_{\mathrm{M}}$ is given by equation (11a).

As equations (15) and (11) indicate, for no scattering the spectral emittance of a uniform temperature cylinder depends on the optical depth, $K_{\mathrm{R}}$, and indices of refraction, $\mathrm{n}_{\mathrm{f}}$ and $\mathrm{n}_{\mathrm{o}}$. For single crystal materials, such as rare earth doped yttrium aluminum garnet (YAG), scattering should be negligible. However, for polycrystalline rare earth oxides such as those being considered in references (1) to (3) scattering should be significant. In those cases equation (15) will overestimate the spectral emittance.

Consider $\varepsilon_{\lambda}$ for the two limiting conditions $K_{R}=0$ and $K_{R} \rightarrow \infty$. The $K_{R}=0$ case corresponds to a wavelength where the material is transparent. While the $K_{R} \rightarrow \infty$ case applies to an emission band of a selective emitter. Since $E_{3}(0)=1 / 2$ and $\lim _{x \rightarrow \infty} E(x)=0$, equation (15) yields the following:

$$
\begin{gathered}
\varepsilon_{\lambda}=0 \quad \text { for } \quad K_{R}=0 \\
\lim _{K_{R} \rightarrow \infty} \varepsilon_{\lambda}=n_{0}^{2}\left(1-\rho_{\text {fo }}\right)
\end{gathered}
$$

Equation (18) is the usual result for an opaque body emitting (or absort ing) in vacuum $\left(\mathrm{n}_{\mathrm{o}}=1\right)$. 


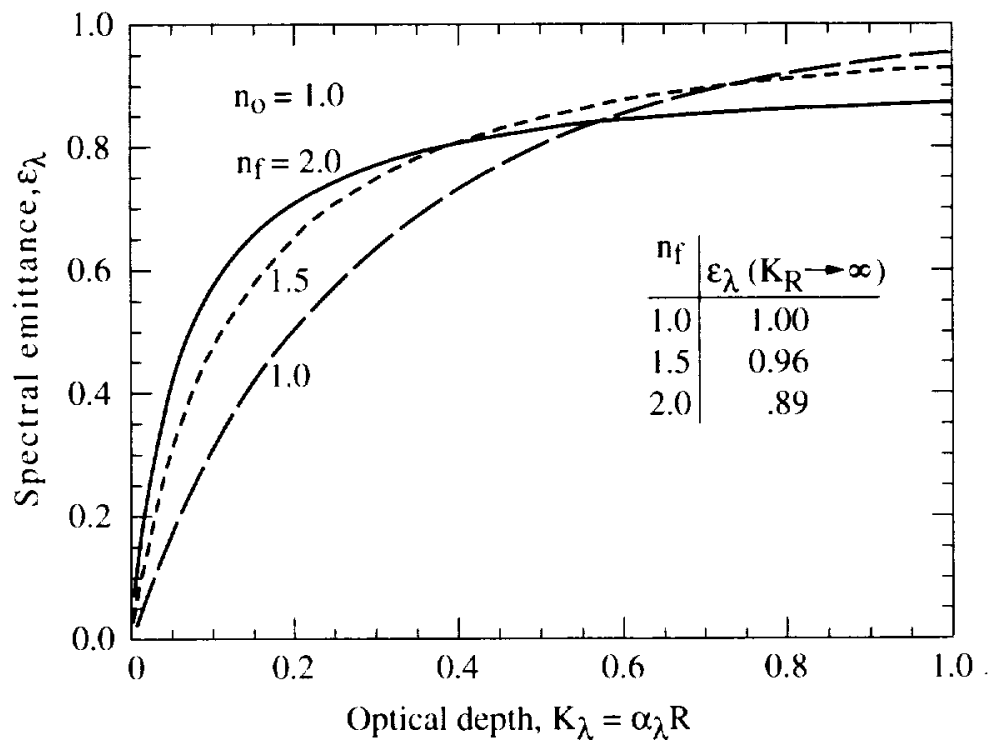

FIGURE 2. Spectral emittance for cylinder of radius, $R$, at a constant temperature, $T_{s}$, as a function of optical depth, $K_{\lambda}=\boldsymbol{\alpha}_{\lambda} R$, where $\boldsymbol{\alpha}_{\boldsymbol{\lambda}}$ is the extinction coefficient and $n_{f}$ is the cylinder index of refraction and $n_{0}$ is the surrounding index of refraction.

In figure 2 the spectral emittance. $\varepsilon_{\lambda}$, using equation (15) is shown as a function of optical depth, $K_{R}$, for $n_{o}=1$ and $\mathrm{n}_{\mathrm{f}}=1,1.5$ and 2.0. As figure 2 shows $\varepsilon_{\lambda}$ increases rapidly with $\mathrm{K}_{\mathrm{R}}$ and reaches nearly its limiting value (eq. (18)) for $K_{R}=1$. Notice also that for small $K_{R}$ as $n_{f}$ increases the spectral emittance rate of increase also increases. For most of the selective emitter materials, $1.5 \leq n_{f} \leq 2.0$.

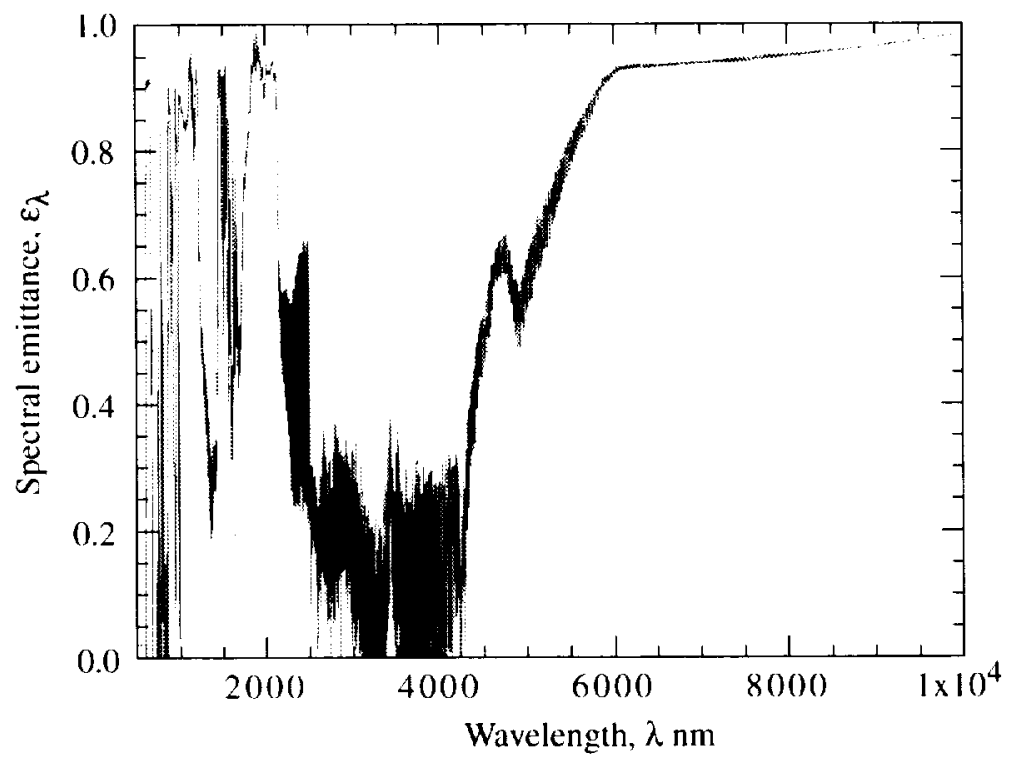

FIGURE 3. Theoretical spectral emittance of $\operatorname{Er}_{0.3} \mathrm{Ho}_{2.7} \mathrm{Al}_{5} \mathrm{O}_{12}$ cylinder of radius, $\mathrm{R}=0.4 \mathrm{~cm}$, calculated using measured extinction coeflicient and index of refraction. 
Once the extinction coefficient, $\alpha_{\lambda}$, and index of refraction, $n_{f}$, are known equation (15) can be used to calculate $\varepsilon_{\lambda}$. Figure 3 shows the calculated spectral emittance for an erbium-holmiun aluminum garnet cylinder $(R=0.4 \mathrm{~cm})$ with $10 \%$ erbium and $90 \%$ holmium, $\mathrm{Er}_{0.3} \mathrm{Ho}_{2.7} \mathrm{Al}_{5} \mathrm{O}_{12}$. This single crystal material is being considered for a film type selective emitter (5). The extinction coefficient and index of refraction were obtained from reference (5). Holmium has its main emission band centered at $\lambda \approx 2000 \mathrm{~nm}$ with smaller bands centered at $\lambda \approx 1100,890$ and $750 \mathrm{~nm}$. Erbium has its main emission band centered at $\lambda \approx 1500 \mathrm{~nm}$ with secondary bands centered at $\lambda \approx 1000$, 800 and $640 \mathrm{~nm}$. All of these hands show up as regions of large emittance in figure 3 . In the region $2000<\lambda$ $<4500 \mathrm{~nm}, \mathrm{Er}_{0.3} \mathrm{Ho}_{2.7} \mathrm{Al}_{5} \mathrm{O}_{12}$ is nearly transparent $\left(\alpha_{\lambda} \rightarrow 0\right)$ and thus $\mathrm{e}_{\gamma_{-}}$is small. The highly oscillatory result in this region results from numerical error in $\alpha_{\lambda}$ (5). For the region $\lambda>\lambda_{c}=5000 \mathrm{~nm} \varepsilon_{\lambda}$ becomes large again. This large $\varepsilon_{\lambda}$ results from vibrational modes of the crystal lattice and is a characteristic of most rare earth selective emitter materials (1). We call the wavelength, $\lambda_{\mathrm{c}}$, the long wavelength cutoff.

\section{EMITTER EFFICIENCY}

As a measure of the effectiveness of a selective emitter define the emitter efficiency as follows.

$$
\eta_{E} \equiv \frac{\text { useful radiated power }}{\text { total radiated power }}=\frac{Q_{b}}{Q_{T}}=\frac{\int_{0}^{\lambda_{g}} q_{\lambda}(R) d \lambda}{\int_{0}^{\infty} q_{\lambda}(R) d \lambda}=\frac{\int_{0}^{\lambda_{g}} \varepsilon_{\lambda} e_{b s}\left(\lambda, T_{s}\right) d \lambda}{\int_{0}^{\infty} \varepsilon_{\lambda} e_{b s}\left(\lambda, T_{s}\right) d \lambda}
$$

The numerator. $Q_{b}$, is the power radiated in the wavelength region $0 \leq \lambda \leq \lambda_{\mathrm{g}}$. In a TPV system $\lambda_{\mathrm{g}}$ corresponds to the bandgap energy, $E_{\mathrm{g}}=\mathrm{hc}_{\mathrm{o}} / \lambda_{\mathrm{g}}$, of the PV cell. The denominator is the total radiated power, $\mathrm{Q}_{\mathrm{T}}$.

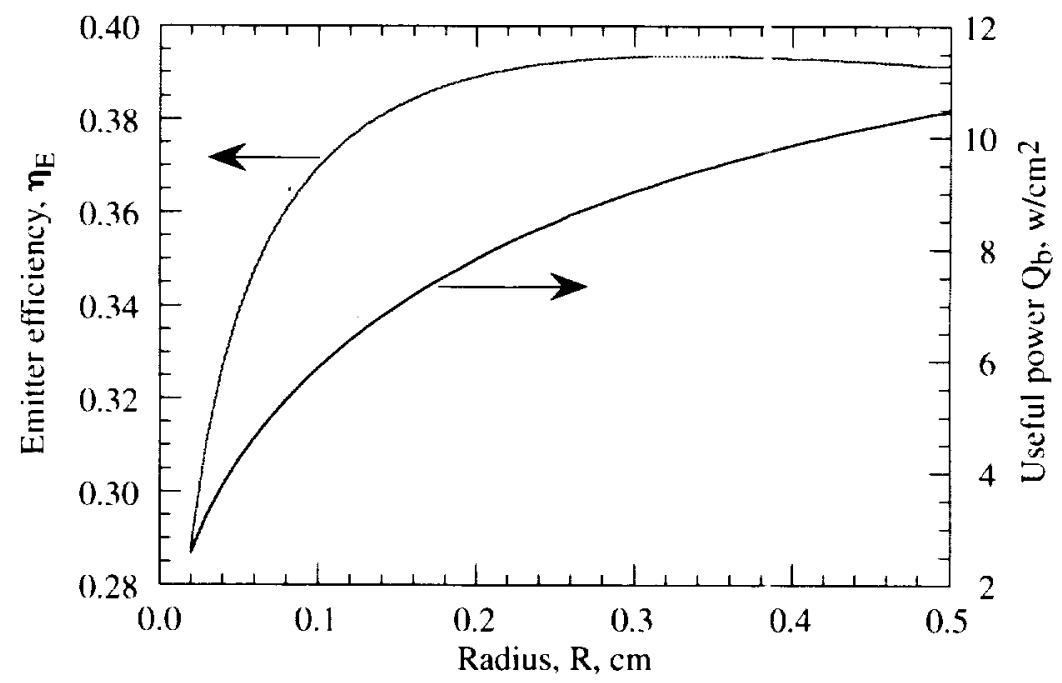

FIGURE 4. Emitter efficiency, $\boldsymbol{\eta}_{\mathrm{E}}$, and useful power, $\mathrm{Q}_{\mathrm{b}}$, as a function of cylinder radius,

$\mathrm{R}$, at emitter temperature, $\mathrm{T}_{\mathrm{s}}=1700 \mathrm{~K}$ for $\mathrm{Er}_{0.3} \mathrm{Ho}_{2.7} \mathrm{Al}_{5}{ }^{()_{12}}$.

Consider how $\eta_{E}$ will be behave as a function of the cylinder radius, R. As figure 2 shows, $\varepsilon_{\lambda}$ increases rapidly with optical depth, $K_{R}=\alpha_{\lambda} R$. Therefore, for the emission bands and the long wavelength region (large $\alpha_{\lambda}$ and $\lambda<\lambda_{\mathrm{g}}$ or $\lambda>\lambda_{\mathrm{c}}$ ) $\varepsilon_{\lambda}$ will quickly approach its limiting value as $\mathrm{R}$ increas es from zero. However, for the regions between the emission bands and the long wavelength cutoff ( $s m a l l \alpha_{\lambda}$ and $\lambda_{1}<\lambda<\lambda_{c}$ ) the spectral emittance will increase more slowly to its limiting value as $R$ increases from zero. Thus, the numerator of equation (19), $Q_{b}$, will rapidly rise from zero to its limiting value as $R$ increases from zero. At the same time, the denominator, $Q_{T}$, will 
increase more slowly and will continue increasing with $\mathrm{R}$ while the numerator is increasing at a much lower rate. As a result, there will be an optimum radius, $\mathrm{R}_{\text {opt }}$, that will yield maximum $\eta_{\text {EMAX }}$. This is illustrated in figure 4 for $\mathrm{Er}_{0.3} \mathrm{Ho}_{2.7} \mathrm{Al}_{5} \mathrm{O}_{12}$ where $\lambda_{\mathrm{g}}=2200 \mathrm{~nm}\left(\mathrm{E}_{\mathrm{g}}=0.56 \mathrm{eV}\right)$ was chosen for use in equation (19) and $\mathrm{T}_{\mathrm{s}}=1700 \mathrm{~K}$. As can be seen, $\eta_{E}$ rises rapidly to $\eta_{E M A X}$ and then decreases slowly for $R>R_{o p r}$. Also shown in figure 4 is the useful power radiated, $Q_{b}$. As can be seen. $Q_{b}$ rises rapidly and then begins to level off. For $T_{s}=1700 \mathrm{~K}$ the optimum radius is $R_{o p t}=0.34 \mathrm{~cm}$. It should be mentioned that for radii of this magnitude the uniform temperature assumption becomes questionable. In figures $5(a)$ and (b) $R_{o p t}, \eta_{F}\left(R_{o p t}\right)$ and $Q_{b}\left(R_{o p t}\right)$ are shown as functions of $T_{s}$. Both $\eta_{\mathrm{F}}\left(R_{\mathrm{opt}}\right)$ and $Q_{\mathrm{b}}\left(\mathrm{R}_{\mathrm{opt}}\right)$ increase significantly with temperature while $R_{\mathrm{opt}}$ decreases only 25 percent in going from $T_{s}=1200$ to $2000 \mathrm{~K}$. The large increase in $\eta_{E}$ results because the maximum value of the blackbody emissive power. $e_{b s}\left(\lambda . T_{s}\right)$, shifts to shorter wavelengths as $T_{s}$ increases. Therefore, $Q_{b}$ increases faster than $Q_{T}$ as $T_{s}$ increases. The useful power, $Q_{h}$, increases at least as $T_{s}^{4}$
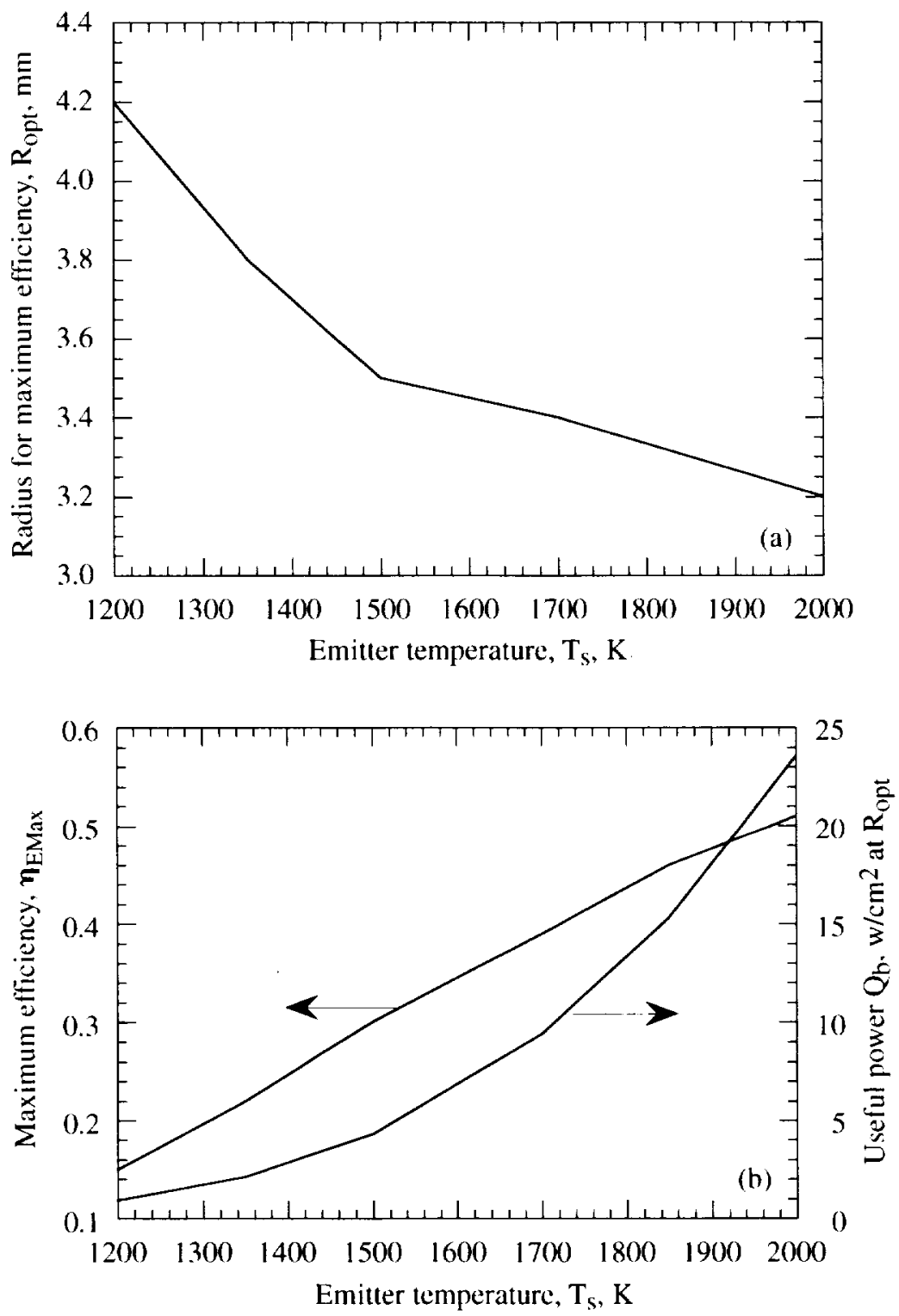

FIGURE 5. Optimum radius, $R_{o p p}$, maximum efficiency, $\eta_{\text {EMax }}$, and useful power, $Q_{b}$, at $\mathrm{R}=\mathrm{R}_{\mathrm{opt}}$ as functions of emitter temperature, $\mathrm{T}_{\mathrm{s}}$, for $\mathrm{Er}_{0.3} \mathrm{Ho}_{2.7} \mathrm{Al}_{5} \mathrm{O}_{12}$. (a) Optimum radius, $R_{\text {opt }}$ (b) Maximum efficiency and useful power. 
Now consider thulium aluminum garnet, $\mathrm{Tm}_{3} \mathrm{Al}_{5} \mathrm{O}_{12}$, as a cylindrical selective emitter. Thulium has its main emission band centered at $\lambda \approx 1700 \mathrm{~nm}$ with smaller bands centered at $\lambda \approx 1200,800$ and $700 \mathrm{~nm}$. Thus compared to $\mathrm{Er}_{0.3} \mathrm{Ho}_{2.7} \mathrm{Al}_{5} \mathrm{O}_{12}$, which has 8 emission bands and thus a large region of high $\varepsilon_{\lambda}$ for $\lambda<\lambda_{\mathrm{g}}, \mathrm{Tm}_{3} \mathrm{Al}_{5} \mathrm{O}_{12}$ has a much smaller high emittance region for $\lambda<\lambda_{\mathrm{g}}$. For $\mathrm{Tm}_{3} \mathrm{Al}_{5} \mathrm{O}_{12} . \lambda_{\mathrm{g}}=1900 \mathrm{~nm}$ was chosen. Just as for $\mathrm{Er}_{0.3} \mathrm{Ho}_{2.7} \mathrm{Al}_{5} \mathrm{O}_{12}$, thulium aluminum garnet has large emittance for $\lambda>\lambda_{\mathrm{c}}=5000 \mathrm{~nm}$.
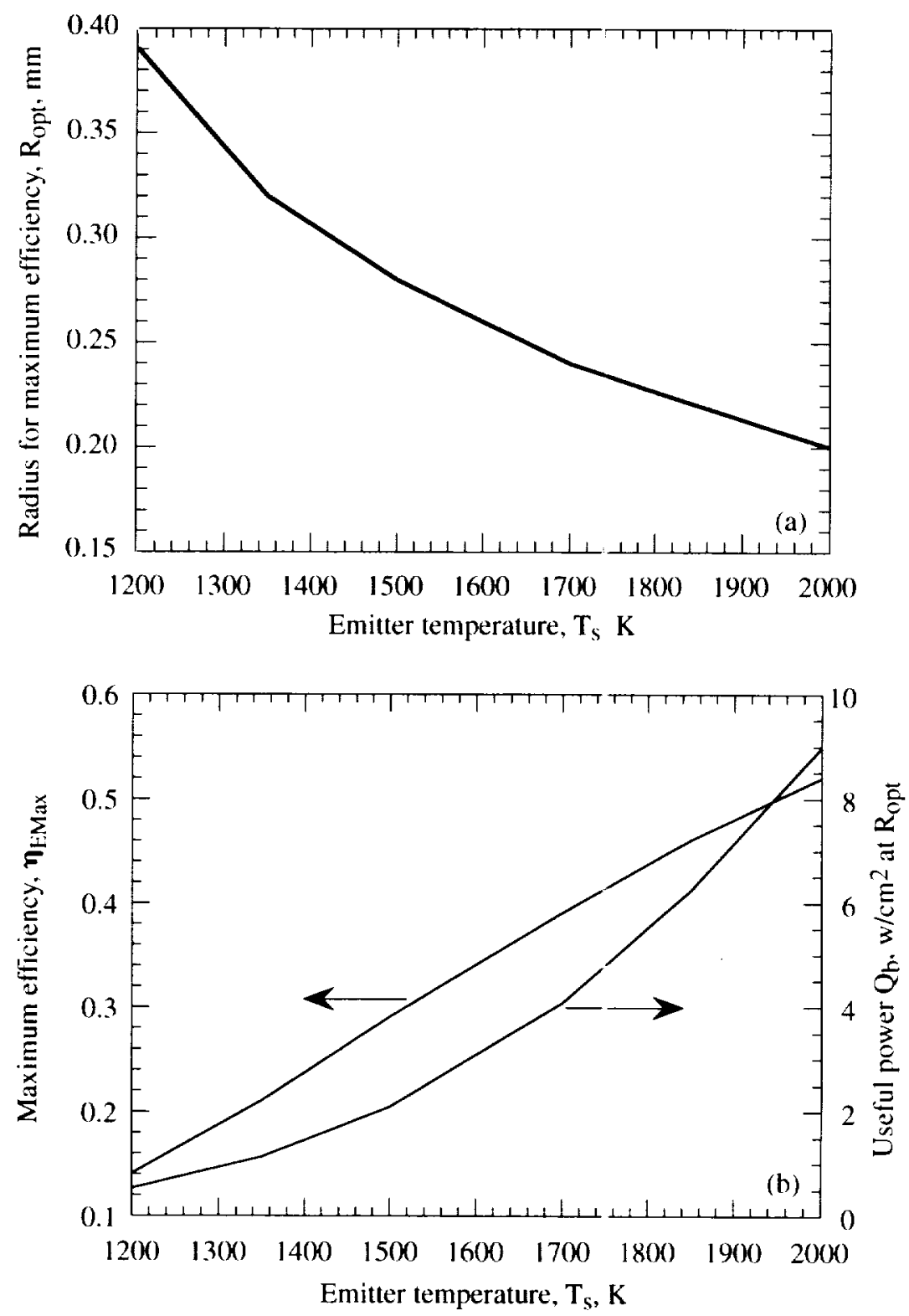

FIGURE 6. Optimum radius, $R_{\mathrm{Opl}}$, maximum efficiency, $\boldsymbol{\eta}_{\mathrm{FMax}}$, and useful power, $\mathrm{Q}_{\mathrm{b}}$, at $\mathrm{R}=\mathrm{R}_{\mathrm{opt}}$ as functions of emitter temperature, $\mathrm{T}_{\mathrm{S}}$, for $7 \mathrm{~m}_{3} \mathrm{Al}_{5} \mathrm{O}_{12}$. (a) Optimum radius, $R_{\text {opt }}$ (b) Maximum efficiency and useful pow:r.

In figure $6(a)$ and (b), $R_{\text {opt }}, \eta_{E}\left(R_{o p t}\right)$ and $Q_{b}\left(R_{o p t}\right)$ are shown as functio is of $T_{s}$ for $T_{3} A_{5} l_{5} O_{12}$. These results were calculated using measured values for $\alpha_{\lambda}$ and $n_{f}(5)$. The first thing to notice is that $R_{\text {opt }}$ for $\operatorname{Tm}_{3} A_{5} \mathrm{O}_{12}$ is much smaller than $\mathrm{R}_{\mathrm{opt}}$ for $\mathrm{Er}_{0.3} \mathrm{Ho}_{2.7} \mathrm{Al}_{5} \mathrm{O}_{12}$. This occurs because thulium aluminum garnet has a smaller region of large emittance than erhium-holmium aluminum-garnet, as mentioned above Therefore, the majority of $\mathrm{Q}_{\mathrm{b}}$ results from emission in the main emission band centered at $\lambda \approx 1900 \mathrm{~nm}$ where $\alpha_{\lambda}=30 \mathrm{~cm}^{-1}$. Thus when $\mathrm{R} \approx 0.3 \mathrm{~mm}, \mathrm{~K}_{\mathrm{R}} \approx 1$ 
and $\varepsilon_{\lambda}$ will be near its maximum value (fig. 2). As a result, $Q_{b}$ will also be near its maximum and thus $\eta_{E}$ will be a maximum. Therefore, we expect that $R_{\text {opt }}$ will occur near $0.3 \mathrm{~mm}$ for thulium aluminium garnet. Figure $6(\mathrm{a})$ substantiates this result.

Comparing figures 5(b) and 6(b) we see that the emitter efficiencies are nearly the same for $\mathrm{Er}_{0.3} \mathrm{Ho}_{2.7} \mathrm{Al}_{5} \mathrm{O}_{12}$ and $\mathrm{Tm}_{3} \mathrm{Al}_{5} \mathrm{O}_{12}$. However, the useful power, $\mathrm{Q}_{\mathrm{b}}$, is much larger for $\mathrm{Er}_{0.3} \mathrm{Ho}_{2.7} \mathrm{Al}_{5} \mathrm{O}_{12}$. This occurs for two reasons. First of all, erbium-holmium aluminum garnet has a much larger region of large emittance for $\lambda<\lambda_{\mathrm{g}}$ than thulium aluminum garnet. Secondly, $\lambda_{\mathrm{g}}=1900 \mathrm{~nm}$ for thulium aluminum garnet whereas $\lambda_{\mathrm{g}}=2200 \mathrm{~nm}$ for erbium-holmium aluminum garnet. Thus more of the spectrum is included in $\mathrm{Q}_{\mathrm{h}}$ for $\mathrm{Er}_{0.3} \mathrm{Ho}_{2.7} \mathrm{Al}_{5} \mathrm{O}_{12}$.

An important point about selective emitters is brought out by comparing figures $5(b)$ and $6(b)$. That is, $\eta_{E}$ and useful power, $Q_{b}$, do not behave in the same manner. Increasing $Q_{b}$ by adding more emission bands, as in the case of $\mathrm{Er}_{0.3} \mathrm{Ho}_{2.7} \mathrm{Al}_{5} \mathrm{O}_{12}$, does not mean that $\eta_{\mathrm{E}}$ will increase.

\section{CONCLUSION}

Most fibrous rare earth selective emitters consist of bundles of 1 to $10 \mu \mathrm{m}$ diameter bundles. In this study that bundle has been approximated as an infinite cylinder. From the solution to the radiative transfer equations the spectral emittance of the cylindrical emitter was calculated. Several conclusions can be made about the cylindrical rare earth selective emitters.

1. For most rare earth selective emitters the temperature is uniform through the cylinder.

2. When the optical depth $K_{R}=\alpha_{\lambda} R \geq 1$ the spectral emittance is nearly a maximum.

3. There is an optimum value for the radius, $R_{o p e}$, which yields maximum emitter efficiency.

4. $R_{\text {opt }}$ strongly depends on the emitter material. For an emitter with only a single strong emission band $R_{o p t}$ is the order of $0.1 \mathrm{~mm}$, whereas for an emitter with many emission bands $\mathrm{R}_{\mathrm{opt}}$ is the order of $1 \mathrm{~mm}$.

5. $\mathrm{R}_{\mathrm{opt}}$ decreases slowly with increasing emitter temperature.

6. The maximum efficiency, $\eta_{\text {EMAX }}$, and useful power, $Q_{b}$, increase significantly with temperature.

\section{REFERENCES}

I. Nelson. R.E., "Thermophotovoltaic Emitter Development." presented at the First NREL Conference on Thermophotovoltaic Generation of Electricity, AIP Proc. 321.80.

2. Holmquist. G.A.. "TPV Power Source Development for an Unmanned Undersea Vehicle," presented at the First NREL Conference, AIP Proc. 321, 308

3. Adair, P.L. and Rose, M.F., "Composite Emitters for TPV Systems." presented at the First NREL Conference. AIP Proc. 321. 245.

4. Chubb. D.L., Good, B.S., Clark, E.B. and Chen, Z., "Effect of Temperature Gradient on Thick Film Selective Emitter Emittance," presented at the Third NREL Conference on Thermophotovoltaic Gencration of Electricity. AIP Proc. 401, 293.

5. Chubb, D.L.. Pal, A.T., Patton, M.O. and Jenkins. P.P., "Rare Earth Doped High Temperature Ceramic Selective Emitters," to be published in the Journal of the European Ceramic Societr, also NASA/TM-1998-208491.

6. Siegel, R. and Howell, J.R., "Thermal Radiation Heat Transfer," 2nd edition. Washington. D.C.. Hemisphere, 1981 , Ch. 4. 


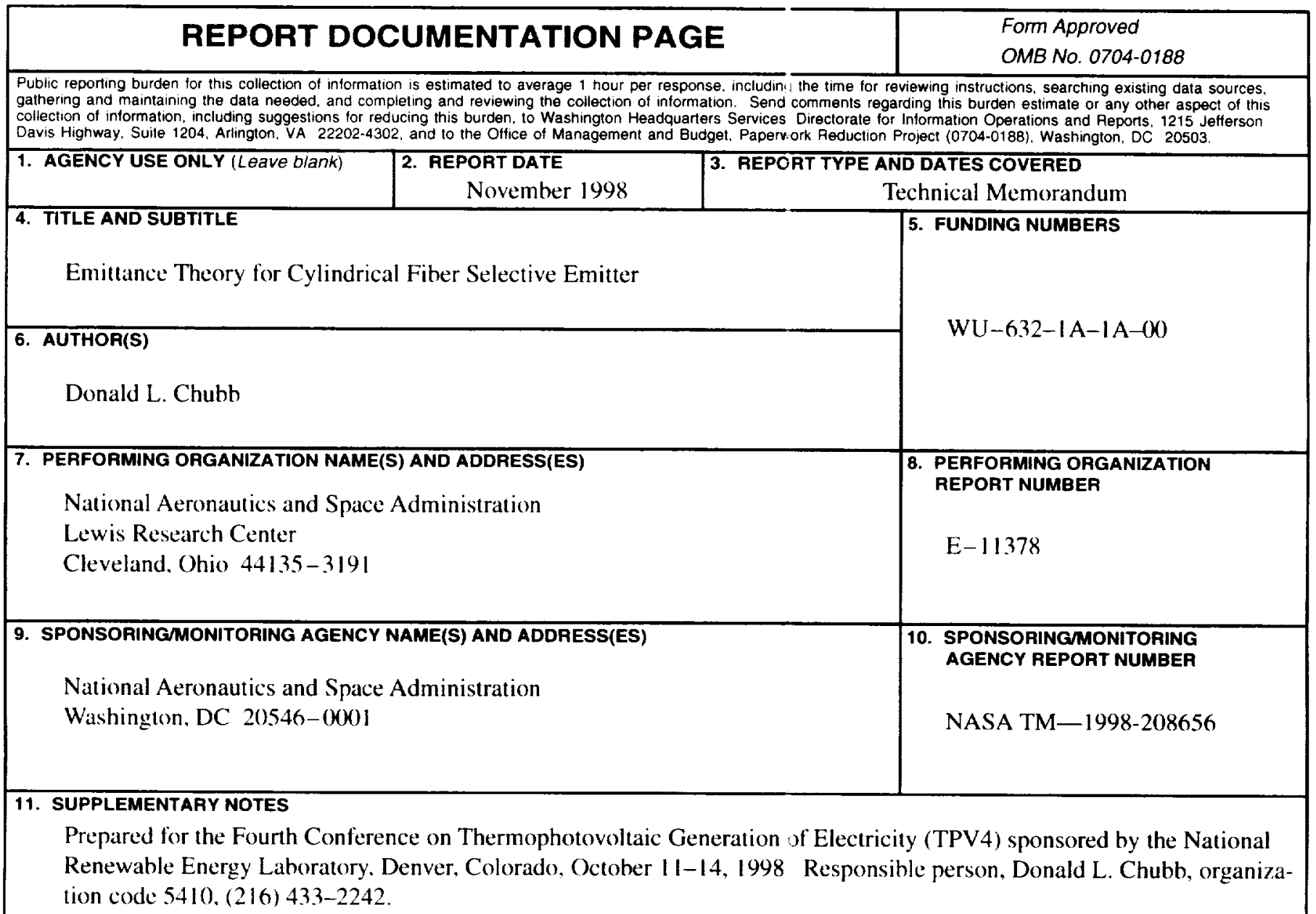

12a. DISTRIBUTIONAVAILABILITY STATEMENT

12b. DISTRIBUTION CODE

Unclassified - Unlimited

Subject Categories: 20 and 76

Distribution: Nonstandard

This publication is available from the NASA Center for AeroSpace Information, (30) 621-0390.

13. ABSTRACT (Maximum 200 words)

A fibrous rare earth selective emitter is approximated as an infinitely lonç cylinder. The spectral emittance, $\varepsilon_{\lambda}$, is obtained by solving the radiative transfer equations with appropriate boundary $c$ onditions and uniform temperature. For optical depths, $K_{R}=\alpha_{\lambda} R$, where $\alpha_{\lambda}$ is the extinction coefficient and $R$ is the cylinder radius, greater than 1 the spectral emittance is nearly at its maximum value. There is an optimum cylinder radius, $R_{o p l}$, for maximum emitter efficiency, $\eta_{\mathrm{E}}$. Values for $R_{\text {opt }}$ are strongly dependent on the number of emission bands of the mat rial. The optimum radius decreases slowly with increasing emitter temperature, while the maximum efficiency and useful radiated power increase rapidly with increasing temperature.

\section{SUBJECT TERMS}

\begin{tabular}{|c|c|}
\hline & 15. NUMBER OF PAGES \\
\hline & 16. PAICE CODE \\
\hline & $\mathrm{A} 03$ \\
\hline $\begin{array}{l}\text { 19. SECUAIT' CLASSIFICATION } \\
\text { OF ABST PACT }\end{array}$ & 20. LIMITATION OF ABSTRACT \\
\hline Urclassified & \\
\hline
\end{tabular}

Thermophotovoltaics: Selective emitter

\begin{tabular}{|c|c|}
\hline $\begin{array}{c}\text { 17. SECURITY CLASSIFICATION } \\
\text { OF REPORT }\end{array}$ & $\begin{array}{c}\text { 18. SECURITY CLASSIFICATION } \\
\text { OF THIS PAGE } \\
\text { Unclassified }\end{array}$ \\
Unclassified
\end{tabular}

